\title{
Natriuresis associated with elevated plasma atrial natriuretic hormone during supraventricular tachycardia
}

\begin{abstract}
Elevated plasma levels of atrial natriuretic hormone (ANH) have been found in patients during paroxysmal supraventricular tachycardia (SVT) and other clinical syndromes. However, physiologic effects of this endogenous ANH have not been demonstrated. To determine whether the rise in ANH during SVT is associated with either a natriuresis or kalluresis, urine sodium and potassium levels were measured in five patients at baseline and during SVT simulated by rapid atrioventricular pacing. Plasma ANH levels increased from $149 \pm 35 \mathrm{pmol} / \mathrm{L}$ at baseline to $187 \pm 31 \mathrm{pmol} / \mathrm{L}(p=0.007)$ during SVT. Plasma vasopressin and renin levels were unchanged. Urine sodium levels increased $49 \%$ from $1.54 \pm 0.66 \mathrm{mEq} / \mathrm{hr}$ at baseline to $2.29 \pm 0.89 \mathrm{mEq} / \mathrm{hr}$ $(p=0.044)$ during SVT, and urine potassium levels increased $22 \%$ from $4.14 \pm 0.10 \mathrm{mEq} / \mathrm{hr}$ to $5.04 \pm 1.25 \mathrm{mEq} / \mathrm{hr}(p=0.018)$. Urine sodium and potassium levels returned to baseline values 1 hour after pacing. Thus elevated plasma levels of ANH during SVT are associated with both a natriuresis and kalluresis, which may represent physiologic effects of the endogenously secreted hormone. (AM HEART J 1989;117:377.)
\end{abstract}

John M. Nicklas, MD, Donald A. Giacherio, MD, David Moskowitz, BS, John H. Lemmer, MD, Marvin M. Kirsh, MD, and Roger J. Grekin, MD. Ann Arbor, Mich.

Vasoactive peptides termed atrial natriuretic hormone (ANH) have been isolated from animal and human atrial tissue, sequenced, and synthesized. ${ }^{1-5}$ Infusion of ANH into animals has been demonstrated to produce an increase in urine, sodium, potassium, and chloride excretion; an increase in glomerular filtration rate and urine flow; an inhibition of aldosterone secretion; a relaxation of vascular smooth muscle; and a systemic hypotensive effect. ${ }^{6-8}$ Infusion of synthetic ANH into normal human volunteers has also produced significant natriuresis, kaliuresis, and diuresis. ${ }^{9,10}$

However, elevated plasma levels of endogenous ANH in patients are not generally associated with high urinary sodium or potassium excretion. Patients with congestive heart failure, chronic mitral stenosis, cor pulmonale, or chronic renal failure with fluid overload have high levels of ANH

From the Department of Internal Medicine, University of Michigan School of Medicine.

Dr. Nicklas is supported by the National Institutes of Health Clinical Investigator Award HL 01170; Dr. Grekin is supported in part by grant HL 18575 from the National Heart, Lung, and Blood Institute and by a grant from the Research Service of the Veterans Administration.

Received for publication Apr. 11, 1988; revision accepted Oct. 14, 1988.

Reprint requests: John M. Nicklas, MD, 3910 Taubman, University of Michigan, 1500 E. Medical Center Dr., Ann Arbor, MI 48109-0366. but frequently retain sodium rather than excrete it into the urine. ${ }^{11-17}$ Although the absence of a natriuresis or kaliuresis in these patients may be a result of other pathologic changes associated with their disease, the persistent sodium retention suggests that the elevated ANH levels may not have a physiologic effect. Therefore, this study was designed to determine whether transient rises in endogenous ANH are associated with a significant natriuresis or kaliuresis. Patients were chosen for study during supraventricular tachycardia (SVT) because previous investigations have demonstrated that this arrhythmia can be accompanied by large (10-fold) increases in plasma ANH. ${ }^{11}$

\section{METHODS}

Patients were studied during SVT simulated by rapid simultaneous pacing of the atrium and ventricle. All subjects had undergone coronary artery bypass operations 2 days before initial study, and atrial and ventricular pacing wires, central venous pressure lines, and indwelling Foley catheters were positioned for the study. Medications were discontinued 12 hours before study except in one patient who received a constant intravenous infusion of dobutamine $10 \mu \mathrm{g} / \mathrm{kg} / \mathrm{min}$ throughout the observation period. Informed written consent was obtained in accord with the University of Michigan Hospital guidelines.

Fifteen-minute urine samples were collected for at least 


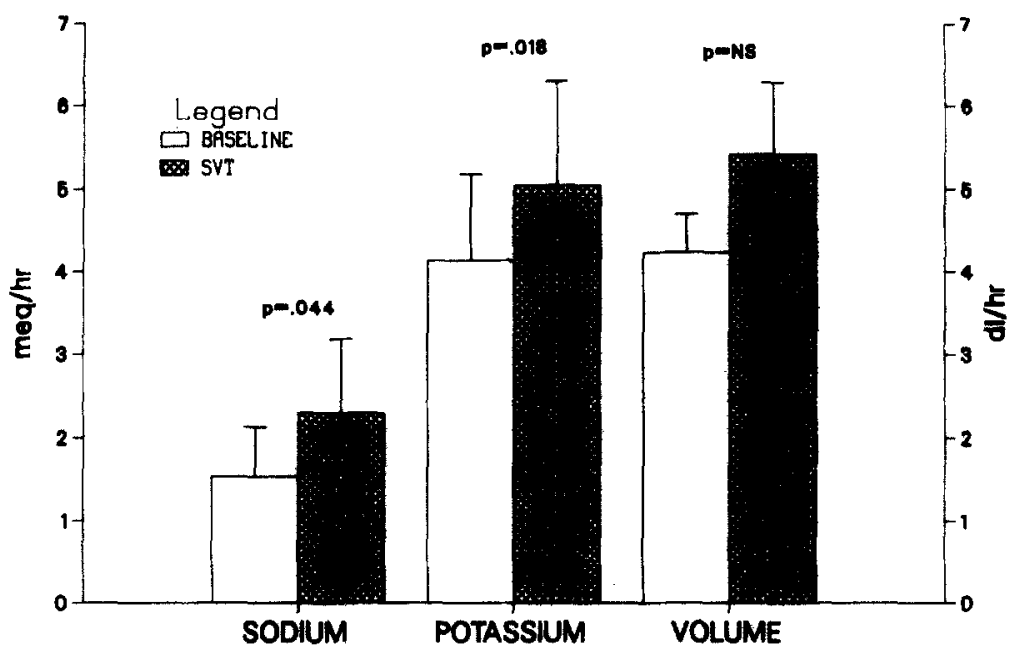

Fig. 1. Urinary volume, sodium, and potassium excretion during baseline and during and for 1 hour after simulated SVT.

2 hours before pacing, during SVT, and for 2 hours after pacing. All patients were considered to have reached a stable baseline urine output defined as three successive collections varying by $\leq 1 \mathrm{ml}$. SVT was then simulated by rapid simultaneous atrioventricular pacing for 15 minutes. Pacing was begun at $140 \mathrm{bpm}$ and increased to $150 \mathrm{bpm}$ after 30 seconds unless discomfort or hypotension developed. One patient experienced nonspecific discomfort at $150 \mathrm{bpm}$ and his rate was reduced to $140 \mathrm{bpm}$. Urine volume, osmolality, and sodium and potassium concentrations were measured in all collections except in one patient who received an intravenous diuretic during the final study hour. Subsequent urine collections in that patient were discarded. Electrolyte concentrations were determined with a Beckman Astra analyzer (Beckman Instruments Inc., San Diego, Calif.) with ion selective electrodes. Urine osmolality was determined with a Precision Systems model 5004 osmometer (Precision Systems, Inc., Sudbury, Mass.).

Arterial blood samples for measurement of ANH, vasopressin, and renin were obtained at baseline immediately before pacing, at the end of pacing, and 30 minutes after termination of pacing. Central venous pressure and arterial pressure were recorded just before each arterial sampling. All blood samples for ANH were collected in tubes containing ethylenediamine tetraacetic acid, placed on ice, and centrifuged. The plasma samples were stored at $-70^{\circ} \mathrm{C}$ and extracted with the use of $\mathrm{C} 18$ octadecylsilane cartridges (Sep-Pak, Waters Associates, Milford, Mass.). The radioimmunoassay was performed with the use of an antibody against 1-28 $\alpha$-human atrial natriuretic polypeptide purchased from Peninsula Laboratories Inc. (Belmont, Calif.). Synthetic atriopeptin III was iodinated with chloramine- $T$ and separated by high-performance liquid chromatography. Monoiodinated peptide was used as a trace. The complete procedure has been previously described. ${ }^{12}$ Vasopressin and renin levels were also measured by standard radioimmunoassays.

SVT was initiated in eight patients. No one had angina or dyspnea during pacing. ${ }^{18}$ However, in three patients the mean arterial pressure fell by more than $10 \mathrm{~mm} \mathrm{Hg}$ at a rate of $140 \mathrm{bpm}$, and these patients were excluded from further study. The remaining five patients constituted the study group. The average age was 57 years (range 48 to 70 ). and all were men. None had had a previous myocardial infarction and each had a preoperative left ventricular ejection fraction $>50 \%$. There was no history of renal dysfunction in any patient defined as a serum creatinine level $>1.5 \mathrm{mg} / \mathrm{dl}$ or previous proteinuria.

Urinary sodium and potassium excretion were expressed as milliequivalents per unit of time. Urine osmolality for periods $>15$ minutes was calculated from the total osmoles per volume. Group differences between patients at baseline and during SVT were compared by a paired $t$ test. Single and multivariate linear regression analyses were used to examine relationships between variables. All group values are expressed as the mean \pm standard error of the mean.

\section{RESULTS}

Plasma levels of ANH increased 26\% $(p=0.0066)$ during SVT and returned to baseline levels within 30 minutes after pacing (Table I). Levels of vasopressin and renin did not change significantly during or after SVT. The baseline plasma level of ANH was significantly elevated compared with that of normal volunteers as measured in this laboraory $(149 \pm 35 \mathrm{pmol} / \mathrm{L}$ versus $18 \pm 2 \mathrm{pmol} / \mathrm{L}$, $p=0.001$ ).

Baseline central venous pressure was $10 \pm 2 \mathrm{~mm}$ $\mathrm{Hg}$, increased to $12 \pm 3 \mathrm{~mm} \mathrm{Hg}$ during SVT, and fell to $11 \pm 2 \mathrm{~mm} \mathrm{Hg}$ after pacing. These changes in pressure were not significant. In addition, there was no relationship between the changes in central venous pressure and plasma ANH, vasopressin, or renin levels. Arterial pressure was not significantly different before $(87 \pm 4 \mathrm{~mm} \mathrm{Hg}$ ), during $(89 \pm 5$ $\mathrm{mm} \mathrm{Hg}$ ), or after $(90 \pm 5 \mathrm{~mm} \mathrm{Hg})$ SVT. 
Table I. Neurohormone levels before, during, and after SVT

\begin{tabular}{lccr}
\hline & $\begin{array}{c}\text { ANH } \\
(\mathrm{pmol} / \mathrm{L})\end{array}$ & $\begin{array}{c}\text { Vasopressin } \\
(\mathrm{ng} / \mathrm{L})\end{array}$ & \multicolumn{1}{c}{$\begin{array}{c}\text { Renin } \\
(\mathrm{ng} / \mathrm{L})\end{array}$} \\
\hline Baseline & $149 \pm 25$ & $6.0 \pm 3.0$ & $10.8 \pm 4.5$ \\
SVT & $187 \pm 31^{*}$ & $8.1 \pm 4.3$ & $8.1 \pm 3.6$ \\
30 min after & $133 \pm 21$ & $5.8 \pm 2.6$ & $8.3 \pm 3.9$ \\
$\quad$ SVT & & & \\
\hline
\end{tabular}

${ }^{*} p=0.007$ versus baseline value.

All patients showed an increase in urine sodium and potassium excretion. The onset of the change in urine electrolytes began during SVT in four patients and during the 15 minutes after pacing in one patient. Increased excretion lasted for $\mathbf{4 5}$ minutes in one patient and for at least 1 hour in the other four patients. Urine sodium levels increased $49 \%$ from $1.54 \pm 0.66 \mathrm{mEq} / \mathrm{hr}$ at baseline to $2.29 \pm 0.89 \mathrm{mEq} /$ hr during SVT and for the hour after SVT $(p=0.044)$ (Fig. 1). Urine potassium levels increased $22 \%$ from $4.14 \pm 0.10 \mathrm{mEq} / \mathrm{hr}$ at baseline to $5.04 \pm 1.25 \mathrm{mEq} / \mathrm{hr}$ during and after pacing $(p=0.018)$. Urine volume showed a small, statistically insignificant increase from $42 \pm 5 \mathrm{ml} / \mathrm{hr}$ at baseline to $54 \pm 9 \mathrm{ml} / \mathrm{hr}$ during and after SVT. Urine osmolality also rose insignificantly from $707 \pm 60 \mathrm{mOsm} / \mathrm{L}$ to $734 \pm 44 \mathrm{mOsm} / \mathrm{L}(p=\mathrm{ns})$. Serial urine collections during the second hour after SVT demonstrated a return to basal urine electrolyte excretion (Fig. 2). Regression analysis showed no linear relationship between the increase in plasma ANH and the change in urine electrolytes expressed either as absolute increments or fractional changes. The addition of other variables including vasopressin and renin did not provide any additional correlation. There was also no correlation between changes in urine volume and osmolality with levels of ANH, vasopressin, or renin.

\section{DISCUSSION}

This study demonstrates that a small rise in plasma ANH levels can be associated with a significant natriuresis and kaliuresis. Plasma $\mathrm{ANH}$ levels increased only $38 \pm 7 \mathrm{pmol} / \mathrm{L}$, a $26 \%$ increment from baseline levels, yet it was still accompanied by increases of $49 \%$ and $22 \%$ in urinary sodium and potassium excretion, respectively. This suggests that endogenous ANH, detected by plasma radioimmunoassay, is physiologically active.

Vasopressin and renin did not change significantly during this study and do not appear to be related to the natriuresis associated with SVT. ${ }^{17}$ However, the effects of minor neurohumoral changes (Table I) may be obscured by the small number of patients.

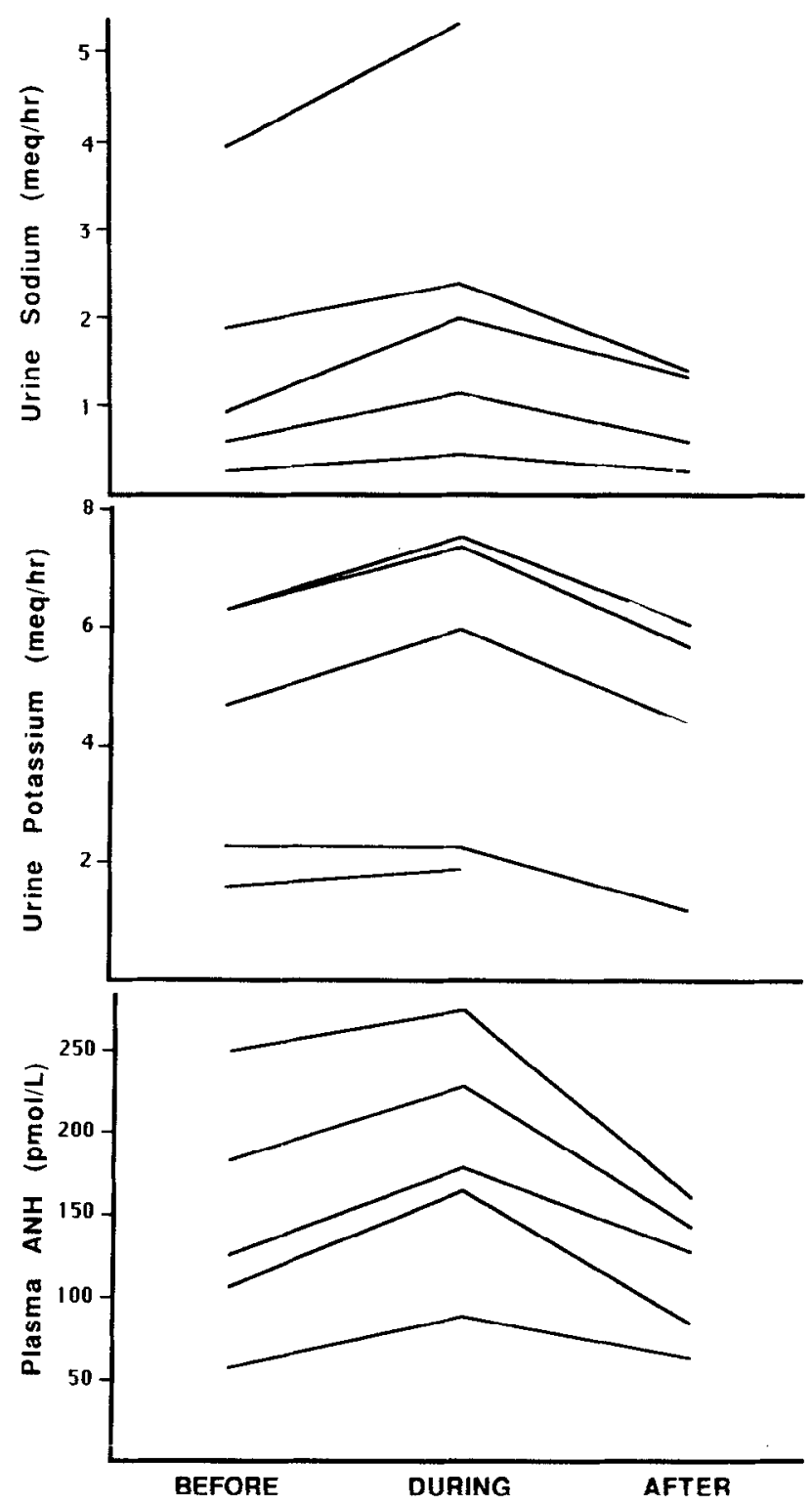

Fig. 2. Serial changes in urine sodium excretion, urine potassium excretion, and plasma $\mathrm{ANH}$ levels in individual patients. Measurements were made before, during, and after simulated SVT.

For example, the increase in vasopressin levels, although not statistically significant, may have contributed to the reduction in urine volume and increase in urine osmolality. The polyuric response typically associated with SVT includes an increase in urine flow, free water clearance, and a fall in urine osmolality, along with an increase in sodium excretion. . $^{19-21}$ The absence of significant changes in urine volume, free water clearance, and urine osmolality may have been due to the elevated central venous pressures at baseline. These high pressures had probably already produced atrial distension and high plasma ANH levels. ${ }^{11-14,22-25}$ Similarly, vasopressin may have been partially suppressed. ${ }^{25,26}$ The 
small additional increment in central venous pressure led to smaller than expected increases in ANH and no significant change in vasopressin. In patients without elevated filling pressures, more dramatic changes in ANH, vasopressin, and urinary excretion could be anticipated.

The natriuresis and kaliuresis in these patients lasted for approximately 1 hour despite the return of ANH to baseline levels within 30 minutes of the termination of SVT. Thus the physiologic effects of ANH appear to persist for 30 to 60 minutes after the original stimulus for secretion and increase in plasma ANH levels have disappeared. Bolus infusions of synthetic $\alpha$-human atrial natriuretic polypeptide have also produced increases in urinary excretion of sodium that last longer than the elevation in measurable plasma levels. ${ }^{9}$ Although an additional natriuretic stimulus could be hypothesized, these observations suggest that ANH alone could account for the increased electrolyte excretion during SVT.

Other experimental data, however, suggest that ANH released as a result of atrial distention is not the sole stimulus for natriuresis. Atrial distention of a denervated heart in a conscious dog can produce significant rises in ANH without a detectable natriuresis. ${ }^{27,28}$ Similarly, a natriuresis after infusions of ANH can be suppressed by decreasing renal perfusion pressure. ${ }^{29}$ Whether cardiac innervation is required for secretion of an active form of $\mathrm{ANH}$ or whether an additional neurohumoral mechanism must be activated or suppressed to permit a natriuresis is unclear. Nevertheless, the temporal relationship of the increase in plasma ANH levels to the natriuresis and the known physiologic properties of ANH suggest that it plays an important role in the natriuresis associated with SVT.

In conclusion, this study demonstrates that a small increase in plasma ANH can be associated with a significant natriuresis and kaliuresis. Thus endogenous ANH as measured by radioimmunoassay appears to have physiologic activity. Furthermore, the natriuresis associated with SVT appears to be modulated, at least in part by plasma levels of ANH.

We wish to acknowledge the skillful support of the Thoracic Intensive Care Unit nursing staff and the excellent secretarial assistance of Ms. Linda Kelley.

\section{REFERENCES}

1. deBold AJ, Borenstein HB, Veress AT, Sonnenberg H. A rapid and potent natriuretic response to intravenous injection of atrial myocardial extract in rats. Life Sci 1981:28:8994.

2. Curie MG, Geller DM, Cole BR, Boylan JF, YuSheng W, Holmberg SE, Needleman P. Bioactive cardiac substance: potent vasorelaxant activity in mammalian atria. Science 1983;221:71-3.

3. Flynn TG, deBold ML, deBold AJ. The amino acid sequence of an atrial peptide with potent diuretic and natriuretic properties. Biochem Biophys Res Commun 1983;117:859-65.

4. Kangawa K, Mats $H$. Purification and complete amino acid sequence of $\alpha$-human atrial natriuretic polypeptide $(\alpha$. hANP). Biochem Biophys Res Commun 1984;118:131-9.

5. Atlas SA, Kleinert HD, Camargo MJ, Januszewica A, Sealey JE, Laragh JH, Schilling JW, Lewicki JA, Johnson LK, Maack T. Purification, sequencing and synthesis of natriuretic and vasoactive rat atrial peptides. Nature 1984;309717-9.

6. Burnett JC Jr, Granger JP, Opgenorth TJ. Effects of synthetic atrial natriuretic factor on renal function and renin release. Am J Physiol 1984;247:F863-6.

7. Maack T, Marion DN, Camargo MJF, Leinert HD, Laragh $\mathrm{JH}$, Vaughan ED, Atlas SA. Effects of auriculin (atrial natriuretic factor) on blood pressure, renal function and the renin-aldosterone system in dogs. Am J Med 1984;77:106975 .

8. Atarashi K, Murlow PF, Franco-Saenz R, Rapp J. Inhibition of aldosterone production by an atrial extracts. Science 1984; 224:992-4.

9. Richards AM, Ikram H, Yandle TG, Nicholls MG, Webster MWI, Espiner EA. Renal hemodynamic and hormonal effects of human alpha atrial natriuretic peptide in healthy volunteers. Lancet 1985;1:545-9.

10. Tikkanen I, Fyhrquist F, Metsarinne K, Leidenius R. Plasma atrial natriuretic peptide in cardiac disease and during infusion in healthy volunteers. Lancet 1981;1:66-9.

11. Nicklas JM, DiCarlo, LA Koller PT, Morady F, Shenker Y, Diltz EA, Grekin RJ. Plasma levels of immunoreactive atrial natriuretic factor increase during supraventricular tachycardia. Am HearT J 1986;112:923-8.

12. Shenker Y, Sider RS, Ostafin EA, Grekin RJ. Plasma levels of immunoreactive atrial natriuretic factor in healthy subjects and in patients with edema. J Clin Invest 1985;76: 1684-7.

13. Bates ER, Shenker Y, Grekin RJ. The relationship between plasma levels of immunoreactive atrial natriuretic hormone and hemodynamic function in man. Circulation 1986;73:115561.

14. Nakaoka H, Imataka K, Fujii J, Ishibashi M, Yamaji T. Plasma levels of atrial natriuretic factor in patients with congestive heart failure. N Engl J Med 1985;313:892-3.

15. Racsher $W$, Tulassay $T$, Lang RE. Atrial natriuretic peptide in plasma of volume overloaded children with chronic renal failure. Lancet 1985;2:303-5.

16. Harter E, Weissel M, Stummvoll HK, Woloszczuk W, Punzengruber C, Ludvik B. Atrial natriuretic peptide concentrations in blood from right atrium in patients with severe heart failure. Lancet 1985;2:93-4.

17. Ogawa $\mathrm{K}$, Ito $\mathrm{T}$, Hashimoto $\mathrm{H}$, Ito $\mathrm{Y}$, Ohno $\mathrm{O}$, Tsuboi $\mathrm{H}$ Takasu N, Tanahashi 'T, Satake T. Plasma atrial natriuretic factor in congestive heart failure [Letter]. Lancet 1986; 1:106.

18. David YB, Shefer A, Weiss AT, Shimon JB, Borman JB Gotsman MS, Lewis BS. Early postoperative assessment of coronary artery bypass surgery using nuclear left ventriculography and atrial pacing. Thorac Cardiovasc Surg 1983; 31:377-81.

19. Canepa-Anson R, Williams M, Marshall J, Mitsuoka T, Lightman S, Sutton R. Mechanism of polyuria and natriuresis in atrioventricular nodal tachycardia. $\mathrm{Br}$ Med J 1984; 289:866-8.

20. Wood P. Polyuria in paroxysmal tachycardia and paroxysmal atrial flutter and fibrillation. Br Heart $J 1963 ; 25: 273-82$.

21. Luria MH, Adelson EL, Lochaya S. Paroxysmal tachycardia with polyuria. Ann Intern Med 1966;65:461-70.

22. Ghose RR, Joekes AM, Kyriacou EH. Renal response to paroxysmal tachyardia. Br Heart J 1965;27:684-7. 
23. Koller PT, Grekin RJ, Nicklas JM. Paradoxical response of plasma atrial natriurtic hormone to pericardiocentesis in cardiac tamponade. Am J Cardiol 1986;59:491-2.

24. Crozier IG, Nickolls MG, Ikram H, Espiner EA. Relation between left atrial diameter and plasma strial natriuretic peptide renin and vasopressin. Am J Cardiol 1986;58: 1134-6.

25. Fater DC, Schultz HD, Sundet WD, Mapes JS, Goetz KL. Effects of left atrial stretch in cardiac-denervated and intact conscious dogs. Am J Physiol 1982;242:H1056-64.

26. Ledsome JR, Wilson N, Ngsee J. Time course of changes in plasma vasopressin during atrial distention. Can $\mathbf{J}$ Physiol Pharmacol 1982;60:1210-8.

27. Goetz KL, Wang BC, Geer PG, Needhleman P. Atriopeptin infusion and left atrial stretch cause similar renal effects in conscious dogs [Abstract]. Fed Proc 1985;44:814.

28. Knapp MF, Hicks MN, Linden RJ, March DASG. Evidence against ANP as a natriuretic hormone during atrial distension. J Endocrinol 1986;109:R5-8.

29. Seymour AA, Smith SG, Mazack EK. Effects of renal perfusion pressure on the natriuresis induced by atrial natriuretic factor. Am J Physiol 1987;253:F234-8.

\title{
Rapid fall in elevated plasma atrial natriuretic peptide levels after successful catheter balloon valvuloplasty of mitral stenosis
}

\begin{abstract}
To determine whether an acute fall in atrial pressure decreases the secretion of atrial natriuretic peptide in man, changes in the plasma levels of this peptide were studied after catheter balloon valvuloplasty of the mitral valve. Ten patients with severe mitral stenosis were included in the study. The valvuloplasty resulted in an immediate reduction in left atrial pressure and an increase in the mitral valve area. Decreases in right atrial pressure were inconsistent and less significant. Plasma atrial natriuretic peptide levels, which were elevated before the valvuloplasty, decreased signiflcantly in all 10 patients at 15 minutes after the valvuloplasty and reached lower plateaus at 30,45 , and 60 minutes after the procedure. In the seven patients studied for a longer period, both plasma atrlal natriuretic peptide levels and the left atrial pressure remained reduced 24 hours after the valvuloplasty. Plasma atrial natriuretic peptide levels before and 30 to 60 minutes after the valvuloplasty were positively correlated to simultaneously determined left and right atrial pressures. These results Indicate that atrial stretch caused by increased atrial pressure is an important stimulus for atrial natriuretic peptide release in man. "De-stretching" of the myocytes of the atria results in rapid inhibition of atrial natriuretic peptide secretion. (AM HEART J 1989;117:381.)
\end{abstract}

Jui-Sung Hung, MD, Morgan Fu, MD, Wen-Jin Cherng, MD, Kanji Inoue, MD, a Rong-Chi Tsai, MD, ${ }^{\mathrm{h}}$ Miyuki Ishibashi, MD, ${ }^{\mathrm{b}}$ and Tohru Yamaji, MD. ${ }^{\mathrm{b}}$

Taipei, Taiwan, Republic of China; Kochi and Tokyo, Japan

It is established that atrial natriuretic peptide (ANP) with potent diuretic, natriuretic, vasodilatatory, and aldosterone-inhibiting activities is secreted from the myocytes of both atria. Plasma levels of ANP are elevated in patients with chronic

From the Section of Cardiology, Department of Medicine, Chang Gung Medical College and Chang Gung Memorial Hospital, Taipei 10590, Taiwan; the Department of 'Thoracic Surgery," Kochi Municipal Hospital; and the Third Department of Internal Medicine, ${ }^{b}$ Faculty of Medicine, University of Tokyo.

Received for publication July 11, 1988; accepted October 14, 1988.

Reprint requests: Jui-Sung Hung, MD, Chang Gung Memorial Hospital 199 Tung Hwa North Rd., Taipei 10590, Taiwan, Republic of China. congestive heart failure with a concomitant increase in atrial pressures. ${ }^{1-3}$ This suggests that atrial stretch plays an important role in increasing ANP secretion in man, as has been evidenced in experimental animals. ${ }^{46}$ Furthermore, our previous observation of a rapid rise in plasma ANP levels after induction of paroxysmal atrial tachycardia by electrical stimulation suggests that atrial myocytes respond rapidly to a rise in atrial pressure by secreting ANP.?

The recent introduction of catheter balloon valvuloplasty (CBV) for the treatment of mitral stenosis $^{8,9}$ has provided a unique human model for the study of changes in ANP secretion before and after a reduction in atrial pressures. Waldman et al. ${ }^{10}$ 